\section{US air pollution is harmful and fine particles can kill}

SIR - Your Special Report on air pollution in the United States ("The politics of breathing" Nature 444, 248-249; 2006) has been criticized for accepting the conclusions of "two large, well-respected epidemiological studies" that long-term exposure to fine particles in the air is associated with increased mortality. Suresh Moolgavkar, in Correspondence ("Pollution analysis flawed by statistical model” Nature 445, 21; 2007), says that there is "by no means universal agreement among scientists that air pollution at contemporary US levels affects human health".

That statement is probably correct. When do we ever see universal agreement about anything? However, he is not correct when he states that "joint pollutant analyses with sulphur dioxide and either sulphates or fine particles both included in the statistical models - show that sulphur dioxide is associated with mortality; fine particles are not".

Moolgavkar refers to D. Krewski and colleagues' Reanalysis of the Harvard Six Cities Study and the American Cancer Society Study of Particulate Air Pollution and Mortality (Health Effects Institute, 2000). But this reanalysis clearly supports the view, which I strongly hold, not only that air pollution at contemporary levels adversely affects health, but also that fine particles are most definitely associated with mortality. For example, on page 31 Krewski et al. state: "Nonetheless, both fine particles and sulphate continued to demonstrate a positive association with mortality even after adjustment for the effects of sulfur dioxide in our spatial regression analyses".

Steve Moorhouse

Environmental Health Division,

Milton Keynes Council, Civic Offices,

Milton Keynes MK9 3HH, UK

\section{Quality evaluation needs some better quality tools}

SIR - In their Commentary "Measures for measures" (Nature 444, 1003-1004; 2006), Sune Lehmann and colleagues report that some widely used research 'quality' evaluation tools based on citation indices are unreliable, because these measures do not minimize statistical uncertainty. This highly interesting study shows, disturbingly, how little evaluation measures have been scrutinized by users so far. However, I would like to point out one additional, major issue.

The quality of publications cannot be measured using citation indices, whatever their statistical reliability. Instead, measures based on received citations assess the visibility of publications, authors or journals, and this may not necessarily correlate well with quality. For instance, if authors criticize a study for using unconvincing methods or for drawing the wrong conclusions, they will still be citing that study, thereby improving its citation record.

Also, when faced with many journals' instructions to limit the number of references, authors have to choose between references of equal quality. The choice of the citing authors will then inevitably rely on other criteria, such as convenience of access; also, geopolitical factors may play a role, as the analysis of citation flow between countries reveals distinct country clusters of citation preferences (A. Schubert \& W. Glänzel Scientometr. 69, 409-428; 2006). Finally, in some cases, authors who cite a paper may not even have read it (M. V. Simkin \& V. P. Roychowdhury Complex Syst. 14, 269-274; 2003).

In my view, there are promising models that could be developed into more targeted quality measures than currently used citation-based indices.

One example is that of the Internet-based commercial bookselling companies that have developed platforms where users - readers - evaluate the quality of publications; here, each evaluation itself can also be evaluated by other readers. The journal Behavioral and Brain Sciences publishes extensive open peer commentary alongside a target article and the authors' response to the comments. A combination of both models, asking peers to briefly evaluate a scientific publication according to several quality parameters (such as quality of methods, completeness, innovative potential or potential of generating beneficial effects to society), might serve better to draw a reliable and targeted picture of research quality than measures that only count citations.

Thomas F. Döring

Division of Biology, Imperial College London, Silwood Park campus, Ascot,

Berkshire SL5 7PY, UK

Readers are welcome to comment on this Correspondence and the Commentary at Nautilus, our blog for authors: http://blogs. nature.com/nautilus/2007/01/post_1.html - Editor, Nature

\section{Fossils: professionals and amateurs can cooperate}

SIR - The statement that "commercial fossil trading in the United States has its roots in the 1960s" in your News story "Palaeontology journal will 'fuel black market" (Nature 445, $234-235 ; 2007)$ is misleading. Parts of the US National Museum of Natural History's collection of invertebrate fossils were bought in the late nineteenth century from amateur collectors. The collector's payment sometimes included a position as a research scientist in the museum as well as money for the material supplied.

The relationship between amateur and professional palaeontologists in the United States has been, and continues to be, a strong and positive one. It is unfortunate that the unscrupulous behaviour of individuals is sometimes misconstrued as revealing a divide between these communities.

Nigel Hughes

Department of Earth Sciences, University of California, Riverside, California 92521, USA

\section{Ignore the spurious claims of private fossil-hoarders}

SIR - Your News story about an 'amateur' journal gives some of the reasons why details of privately held fossils should not be published ("Palaeontology journal will 'fuel black market”" Nature 445, 234-235; 2007). I would add that fossils in private collections are not essential to science.

Some very naive students of palaeontology think that finding new fossils is the only way to make an advance in the field. However, palaeontology is only one of many sciences studying evolution. The meaning of fossils as a whole and as individual specimens - is linked to the other sciences and changes with the progress made in them.

Fossils found in the time of Georges Cuvier, for example, are no longer interpreted in the way that this remarkable scientist interpreted them 200 years ago. They do not have the same meaning. But as long as they remain available, they can be studied anew in the light of new knowledge. Our knowledge of evolution has changed since Cuvier's time: the geological context is better understood, the discovery of other fossils allows a better understanding of their relationships and new techniques give rise to new observations. So the fossils found in his time can be studied productively time and time again.

Fossils are eternal, and this is the main reason why we have public museums. In these institutions, all fossil specimens must be available for research and presentation to the public. We do not need fossils kept in private collections and available only to a few favoured people.

Jean-Louis Hartenberger

Laboratoire de Paléontologie cc 64, Institut des Sciences de l'Évolution, Université Montpellier 2, 34095 Montpellier cedex 5, France

Contributions to Correspondence may be submitted to corres@nature.com. They should be no longer than $\mathbf{5 0 0}$ words, and ideally shorter. Published contributions are edited. 